\title{
Obesity and Nutrition Epidemiology: A Study of Cause and Effect
}

\author{
Cheryl Ann Alexander ${ }^{1,2}$, Lidong Wang ${ }^{3, *}$ \\ ${ }^{1}$ Department of Nursing, University of Phoenix, USA \\ ${ }^{2}$ Technology and Healthcare Solutions, Inc., USA \\ ${ }^{3}$ Department of Engineering Technology, Mississippi Valley State University, USA \\ *Corresponding author: lwang22@students.tntech.edu
}

Received December 05, 2014; Revised February 04, 2015; Accepted February 09, 2015

\begin{abstract}
Obesity has become a matter of quality to health care administrators. Today there are more obese people in the U.S. than ever before. A diet high in fat combined with a sedentary lifestyle has led many Americans to increase their weight to shocking proportions. The Centers for Disease Control report that 34.2\% of Americans over 20 are overweight, 33.8\% are obese, and 5.7\% are extremely obese. Administrators and health care leaders need to care about these numbers as health care dollars spent on treating the complications associated with obesity rise every year and contribute to lost dollars in terms of repeated admissions for complications associated with obesity. The National Guideline Clearinghouse has developed performance indicators for obesity education upon discharge from inpatient settings. By coming up with innovative strategies for combatting obesity, administrators can contribute to the decrease of a world-wide epidemic.
\end{abstract}

Keywords: obesity, dietary surveys, metabolic studies, nutrition epidemiology, nutrition and physical activity, nutrition and metabolic syndrome

Cite This Article: Cheryl Ann Alexander, and Lidong Wang, "Obesity and Nutrition Epidemiology: A Study of Cause and Effect.” World Journal of Nutrition and Health, vol. 3, no. 1 (2015): 8-15. doi: 10.12691/jnh-3-1-2.

\section{Introduction}

In today's society, health promotion is key to saving both health care costs and saving patients from potentially debilitating chronic conditions. Promoting healthy behaviors is not a new concept to nursing, but the focus of health promotion is rapidly gaining more attention since the introduction of the health care reform act. Nurses should encourage patients in promoting healthy behaviors to prevent chronic diseases such as heart disease, diabetes, and high blood pressure and to prevent worsening of patients already diagnosed with chronic disease. With diet control and exercise along with regular check-ups, patients can prevent many of the complications associated with lifelong debilitating disease. The costs of chronic disease have skyrocketed over the last decade as health care agencies have seen an increase in the number of chronically ill patients and an increase in the number of patients over the age of 65. In this paper, the definition of a concept will be explained, two articles will be reviewed on concept analysis of healthy behavior promotion, the definition of healthy behavior promotion will be explored among other disciplines, and applications to clinical practice will be explored. A concept analysis is an indepth analysis of the concept through a review of the literature (McEwen \& Wills, 2011). Some concepts are abstract and some concepts are more concrete. According to McEwen and Wills (2011), as concepts become more abstract, they become less measurable and require indirect measures for analysis. Healthy behavior promotion is a more abstract concept and requires more indirect measures for analysis.

Health promotion is central to nursing. Nurses traditionally equate health promotion with healthy behavior education. However in the study conducted by Irvine (2007), it was determined that this is not always the case. Health promotion meant lifestyle changes, individual responsibility, education and advice, offering choices, and optimum health (Irvine, 2007). This definition of healthy behavior promotion is better-rounded than the traditional educational model and requires the patient to be more accountable for his or her actions and take part in a regimented plan that offers the end result of optimum health, whether it is the maintenance of a chronic illness or the absence of a chronic illness.

Maben and Clark (1995) tried to present an evolutionary context in which health promotion could be examined and not the traditional static method dictated by the relevant concept analysis techniques used today. Maben and Clark (1995) first defined health as "freedom from disease" and "absence of illness." Although this limited the use of the concept for patients already with chronic disease, the concept idea was a good one. The researchers then defined health promotion as the promotion of healthy behaviors that will encourage wellbeing. Health promotion and health education are synonymous. Not only do healthy behaviors come from healthy activities, but people must be educated to receive 
the necessary information to perform these healthy behaviors. Health is a life-style behavior change (Maben \& Clark, 1995). Old lifestyles must be put aside and new lifestyles adopted once healthy behaviors are achieved.

From Irvine's (2007) and Maben and Clark’s (1995) standpoint, health promotion is holistic. Other disciplines such as physical therapy or occupational therapy view health promotion from the viewpoint that return to functioning is health promotion. The difference in education and attention to self-care, offering choices, and optimum functioning are main topic disparities (Irvine, 2007). Whitehead (2009) writes that many patients need a serious incentive to change healthy behaviors and most nurses do not know how to relate to these needs. The researcher goes further to say that nurses may already be adding knowledge that the patient already knows and chooses not to follow. Psychologists however, believe that the underlying root in these problems is the resistance to change and approach health promotion from a standpoint of psychosocial change (Whitehead, 2009).

There are many applications to promote healthy behavior in clinical settings. One innovative and cuttingedge technology is being used in scattered parts of the U.S. Home-based telemedicine to monitor weight, oxygen saturation, and heart rate promote healthy behaviors by keeping the patients at home and maintaining close contact with physicians and nurses. Daily nurse-patient conferences via televised laptop or iPad conferences on patient education about diet, exercise, meal planning, selfcare, diabetes care, asthma care, heart failure care, and other chronic disease care is typically used. These telemedicine programs are being used to change lifestyles. Radio frequency identification (RFID) sensors or wristbands can be worn to detect data without having to connect to wires or phone lines. Patient tracking is also done to determine how much exercise the patient is getting and how well the patient is adhering to the prescribed program; perhaps for an outpatient knee replacement or hip replacement.

Healthy behavior promotion is necessary for the reduction of health care costs and the promotion of patient health. Through concept analysis, nurse researchers and doctorally prepared nurses can ensure patients are receiving the best in education and health promotion. While other disciplines may look at health promotion differently, the end result is the same; health promotion for the patient.

\section{Obesity: A Question of Quality Health Care}

\subsection{Obesity and Metabolic Studies}

Quality health care is an issue many administrators face. Quality health care can mean anything from patient safety to stroke prevention. One quality issue facing health care administrators everywhere is obesity. Today there are more obese people in the U.S. than ever before. A diet high in fat combined with a sedentary lifestyle has led many Americans to increase their weight to shocking proportions. The Centers for Disease Control (CDC, 2011) report that $34.2 \%$ of Americans over 20 are overweight, $33.8 \%$ are obese, and $5.7 \%$ are extremely obese. Body mass index (BMI), expressed as weight in kilograms divided by height in meters squared $(\mathrm{kg} / \mathrm{m} 2)$, is commonly used to classify overweight (BMI 25.0-29.9), obesity (BMI greater than or equal to 30.0), and extreme obesity (BMI greater than or equal to 40.0; CDC, 2011). Obesity can lead to such diseases as diabetes, heart disease, and stroke. The prevalence of obesity has increased from $13.7 \%$ to $27 \%$ in the last 40 years (U.S. Preventive Services Task Force, 2007). The total number of Americans aged 20 or over who have been told by their physician that they are overweight is 65.9\% (Agency for Health Care Research \& Quality, 2011). Administrators and health care leaders need to care about these numbers as health care dollars spent on treating the complications associated with obesity rise every year and contribute to lost dollars in terms of repeated admissions for complications associated with obesity. Health care leaders and stakeholders alike need to be aware of the rising obesity trend and make a concerted effort to educate and promote a healthy lifestyle. The purpose of this paper is to examine the role of the administrator in the hospital setting and how health care quality and adult obesity are an issue of concern that affect the facility and health care service delivery.

Obesity results when energy expenditure does not equal energy intake. This results in a permanent increase in white adipose tissue. Since 1980, obesity has been increasing in prevalence among all ages and especially in young children. This could be due to a lack of strict diet control among children and obese parents who have already established an inappropriate way to control the appetite.

\subsection{Nutritional Epidemiology}

In 2008, medical costs associated with obesity were estimated at $\$ 147$ billion. The medical costs paid by thirdparty payers for people who are obese were $\$ 1,429$ higher than those of normal weight (CDC, 2011). The cost to health facilities is overwhelming. Health care leaders and administrators should take action to educate and promote a healthy lifestyle to selected populations to reduce thirdparty pricing and prevent costly complications such as falls, wounds, and other complications that are common in the hospital. Leaders should become engaged in the battle against obesity and find ways to cut costs associated with obesity related illnesses and the cost of health care spending by third-party payers and government-based insurance programs (Lovejoy, 2011). As a chief executive officer (CEO), the most important job is to promote quality care within the hospital setting. Finding winning solutions for the treatment of obesity is imperative in saving health care dollars and creating a major impact on saving hospitals thousands of dollars in lost revenue due to complications related to obesity such as poor wound healing and falls (Gade, Gade, Collins, Schmidt, \& Schupp, 2010). Obesity affects nearly half the people in the United States; more than any other disease yet. It is a killer if left alone. Only through a team of health care professionals working together will states defeat obesity and reach Healthy People 2020 goals of decreasing obesity by $10 \%$ in the population; from $34.6 \%$ to $30.4 \%$ based on 2005-2008 data (Healthy People, 2020, 2011). Obesity began to rise as fast food joints became mainstay 
for meals for both adults and children, too busy with work and school to cook at home. A high fat diet, like those typically seen in the Southern States also contributes to obesity. With the rise in cost of healthy food, making wise food choices may seem harder than usual in the current economic crisis. A more sedentary America has contributed to the rise in obesity as well. Many children play video games and use the computer rather than play outside. This lack of physical activity leads to a loss of value for physical fitness. It is important to recognize these factors as contributing to a fatter and more obese America so that health care providers and administrators can develop effective programs to combat the lack of physical activity and influence of high fat, unhealthy foods. Table 1 shows prevalence of overweight children in nursery school (Wandia et al., 2014).

Table 1. Prevalence of overweight and obesity among nursing school children (The number of children $n=320$ )

\begin{tabular}{|c|c|c|c|c|}
\hline Status & Overweight & Obesity & Underweight & Normal \\
\hline Percentage (\%) & 13.4 & 6.9 & 14.8 & 64.9 \\
\hline
\end{tabular}

In 1962 obesity prevalence among adults 20-74 was 13.4\%; by 2006, that number had nearly tripled to $35.1 \%$. There is no limit to the socioeconomic group that is affected by obesity. While the U.S. is not the only country to suffer from the obesity epidemic, it does lead in the number of obese people. Although obesity continues to rise among the economically advanced countries of the world, little has been done to combat the disease. Many health care providers simply ignore the problem and health care administrators offer no creative solutions for fighting the disease (Bhattacharya \& Sood, 2011).

Obesity has a direct relationship with several chronic illnesses. Diabetes, heart disease, hyperlipidemia, and stroke are leading causes of death among obese patients. The cost of treatment for these diseases and the cost of treatment of complications associated with these diseases greatly impact the health care budget of many organizations. Studies show that obese patients spend more dollars on health care than normal weight people. The disparity in costs only increase with age. With programs that address costs, organizations may reduce out-of-pocket expenses noted in the care of obese patients (Bhattacharya \& Sood, 2011).

For Mississippi Baptist Medical Center (MBHS), obesity is an ongoing problem. Administrators are faced with a growing population of obese children and adults. Complications associated with obesity account for many admissions. The leaders and stakeholders of MBHS have to determine a way to reach the community to combat this growing problem that is impacting the hospital and employees.

Colombi and Wood (2011) write that obesity is not only bad for the health of the individual, but bad for the health of the nation. In 2008, the annual indirect costs related to obesity were $\$ 148$ million. The contributions to these costs include lost time at work, increased workers' compensation, presenteeism (being at work but being unproductive), direct medical costs, and costs attributable to the contribution of obesity to the development and exacerbation of a chronic condition. In an attempt to "bend the curve down," fiscal approaches have been suggested such as addressing patient needs beyond the clinical encounter. Wellness programs also comprise a multifactorial approach to health improvement and health promotion, including the management of chronic conditions (Colombi \& Wood, 2011). It is important for administrators to recognize the value in these programs because employees may lose time at work, cost more in medical payments, and be unproductive.

Physicians play an important role in the quality of health care associated obesity. Physicians should counsel patients to lose weight. Patients generally report a positive experience in losing weight after counseling by a physician (Jay et al., 2010). Some reasons a physician may not be successful in counseling an obese patient are lack of time, lack of understanding obesity, and poor attitude toward obesity. Jay et al. (2010) suggest that several reasons exist for a successful session on obesity counseling based on their qualitative study. A patientcentered program is most useful, where counseling exists on a one-to-one basis using structured assessment and counseling, and provides the patient with realistic solutions to their primary problems of inactivity and diet will likely lead to more successes than failures.

Over the next three to five years the trend for obesity will continue to rise. Energetic administrators are needed on the forefront that take initiative and develop creative programs to help not only patients, but employees in losing weight and reducing the burden of cost in health care. With the rising food prices and the impending health care reform, savvy administrators will develop key programs that help employees and patients target physical inactivity, overeating, and chronic disease. This is important to reduce not only the number of health care dollars spent per year that are not covered by insurance, but to improve the health of the nation over the next three to five years.

\section{Nutrition and Leadership}

\subsection{Local Population and Administrators}

By state, Mississippi has the largest number of obese patients in the nation; 34\% on average. Colorado comes in last at 21\% (CDC, 2011). Other states are now reaching Mississippi's average as the obesity epidemic grows exponentially and health care providers sit idly by and do nothing to intervene. Obesity is not related to socioeconomic status or education. Many times it is widespread and equally distributed among the upper class privileged citizens and the lower class non-privileged children (CDC, 2011). The South has the highest prevalence rate $(29.4 \%)$, followed by the Midwest (28.7\%), Northeast (24.9\%) and the West (24.1\%). Administrators feel the impact of obese patients in hospitals and clinics as larger equipment is necessary, longer stays are needed for healing, complications related to obesity such as respiratory difficulties are difficult to get reimbursement for and sometimes can leave the hospital holding a large bill. Administrators may not have direct clinical contact with the obese patient, but health care spending and hospital preparedness needs to be considered for quality.

\subsection{Path for Administration}

Approximately $17.5 \%$ of teenagers over 12 are overweight. Obesity rates for teens and children have 
almost tripled since the 1990's. Low income is a contributing factor to weight gain for some teens according to a report by the CDC (2011). The number of obese teenagers $12-19$-years-old is $17.1 \%$, children ages 6-11 is already at $19.6 \%$, and $2-5$-year-olds who are obese is $10.4 \%$ (CDC, 2011). It is concerning that children ages 6-ll are already reaching exponential percentages as bad eating habits, lack of exercise, lack of public agency support have led to such alarming numbers. Obesity education should begin, therefore, with the very young. Administrators can initiate programs that reach young children, offer healthy nutrition ideas, and get physician involvement in child obesity before it becomes a problem. Intervening in child obesity is where adult obesity begins to change.

\subsection{Nutrition and Poverty}

Overall, obesity increases when level of income decreases. At least $29 \%$ of women who live $350 \%$ below the poverty level are obese. Similarly, $42.0 \%$ of those with income below $130 \%$ of the poverty level are obese. Of the approximately 72 and a half million adults who are obese, $41 \%$ (about 30 million) have incomes at or above $350 \%$ of the poverty level, 39\% (over 28 million) have incomes between $130 \%$ and $350 \%$ of the poverty level, and $20 \%$ (almost 15 million) have incomes below $130 \%$ of the poverty level. It can be assumed that poverty level has limited effect on obesity statistics overall. There is no significant trend among adults with incomes above the poverty level as opposed to those below the poverty level for obesity (CDC, 2011). There is an unprecedented level of support for obesity prevention in the Affordable Care Act of 2010. Obesity puts adults and children at risk for over 20 major diseases and including type 2 Diabetes and heart disease. Obesity and obesity-related illness costs continue to drive up health care costs and promote a less productive workforce (Lizzo-Mourey \& Levi, 2011). Because of these troubling statistics, it is important for administrators, stakeholders, and medical professionals to gather together and foster an environment of support by removing obstacles to making healthy choices and creating more choices for healthy living-particularly for those people whose choices have been limited.

\section{Why Patients do not Follow Up}

The U.S. Preventive Task Force (2011) currently recommends screening for obesity as well as other related chronic diseases such as diabetes, heart disease, and lipid disorders. However, people in low income or rural areas are less likely to come in and have screenings done for chronic disease and obesity or make lifestyle changes that would prevent chronic disease from developing. Traveling a long distance to a health care provider is another reason some patients do not follow up with medical problems or get treatment early (Murimi \& Harpel, 2010). In the Murimi and Harpel (2010) qualitative study, barriers to health care were identified such as fear, lack of time, low priority, and lack of companionship. These factors and others must be addressed by health care leaders and administrators to address the problem of obesity as it relates to the hospital setting. Having open sessions where patients can openly ask questions and have their questions answered honestly and with dignity is one way to get patients involved. Self-help groups are another way to advocate for the prevention and solution to obesity.

Lazarou and Kouta (2010) discuss the role of nurses in preventing obesity. It is estimated that even a $10 \%$ increase in body fat is responsible for cardiovascular disease, increased lipidemia, and at least $75 \%$ of cases of hypertension can be traced to obesity. A BMI of 30 carries a risk three times higher than that of a BMI of 25 for diabetes. Nurses are prime candidates for health educators and role models as they are normally at the bedside more often and in close relationships with patients. In the hospital setting, it is easy for discharge teaching to include healthy eating teaching and quality of care teaching about obesity and diet (Lazarou \& Kouta, 2010).

\section{Obesity Prevention}

\subsection{Obesity Prevention begins in Childhood}

Obesity prevention begins in childhood when behaviors are easily altered and behavior modification is not as difficult as adult behavior modification. It is important to look at factors that contribute to the rise of obesity starting in childhood and try to prevent them if possible. With the dramatic increase in cost associated with obese children, it is more important than ever for administrators and hospital leaders to take a look at programs that can assist the public in fighting this rising epidemic. The medical profession has gained momentum in diagnosing, treating, and intervening in cases of childhood obesity (Haemer et al., 2011). Understanding the role these factors play is important in understanding what it takes to make a healthy adult. Recommendations by the CDC and World Health Organization (WHO) for average growth of healthy infants and children ensure that proper diet and exercise is incorporated for the infant and child. Later risk factors for adult diseases can be diminished or even prevented with serious attention to weight and exercise in childhood (Dolinsky et al., 2011). Table 2 shows characteristics of children who are obese (Wandia et al., 2014).

Table 2. Characteristics of the study sample (sample size $n=320$ )

\begin{tabular}{|l|c|c|}
\hline \multicolumn{1}{|c|}{ Characteristic } & $\begin{array}{c}\text { The number of } \\
\text { children with the } \\
\text { characteristic }(\boldsymbol{N})\end{array}$ & Percentage (\%) \\
\hline Family has television & 225 & 70.3 \\
\hline Child watches television & 216 & 96.9 \\
\hline Family has computer & 106 & 33.2 \\
\hline Child plays computer games & 28 & 26.4 \\
\hline Child plays games in estate & 319 & 99.7 \\
\hline Enough room for playing & 307 & 95.9 \\
\hline $\begin{array}{l}\text { Child participates in physical } \\
\text { education in school }\end{array}$ & 318 & 99.4 \\
\hline Child eats in school & 280 & 87.5 \\
\hline Child carries packed lunch & 27 & 8.5 \\
\hline Child buys snacks & 27 & 8.5 \\
\hline
\end{tabular}

\subsection{Management of Obesity and Prevention Modalities}

The role of health care leaders in prevention of obesity is emerging. Over the last decade the CDC and Agency 
for Health care Research and Quality (AHRQ) have found that health care leaders, physicians, and nurses are in key positions to advance the prevention of obesity (AHRQ, 2011; CDC, 2011). Prevention strategies begin with childhood obesity. It is estimated that childhood obesity is on the rise with more and more parents being obese and unhealthy lifestyles and food choices making it easy for children and teenagers to become overweight (Dolinsky et al., 2011). There are several treatment modalities available for adults with obesity. Health care dollars can saved by promoting the use of one or more of these treatment modalities as well as less time off from work related to obesity complications and other chronic illness due to obesity (Meires \& Christie, 2011).

Management of childhood obesity in New York City, NY, USA has become more appropriate and productive in the last few years thanks to a revamp of the Supplemental Nutrition Program for Women, Infants, and Children (SNAPS). A more lean approach to nutrition and the emphasis of exercise to children in need of nutritional counseling has been successful. In kindergarten through eighth grade, special meal preparation in the public schools has led to a more lean and increased nutritional value for meals (2014).

In today's society, experts agree that Americans are becoming more obese (Hammond \& Levine, 2010). With such a growth of the obese population, long-term effects on the economic impact of health care organizations and the work place need to be examined. Colombi and Wood (2011) examined the economic impact of obesity on the workforce as it related to cardiovascular disease, diabetes, and hypertension. These chronic diseases are a major source of missed work days and loss of productivity on job sites for employees who are obese, not to mention skyrocketing costs of medical bills for insured employees who are members of a group plan (Colombi \& Wood, 2011).

According to the Centers for Disease Control (CMS), the overall health expenditures for an obese person are $\$ 1,429$ higher than that of an average weight individual. The American Heart Association has called for extreme measures in combating heart disease and obesity (Colombi \& Wood, 2011). For the financially stressed company or for the small business owner who may not have the capital to spend on excessive health care expenses, obese employees can significantly burden the system with chronic illness and lost productivity. With health care reform looming around the corner dictating health insurance plans for everyone, small business owners could find themselves spending more on health care than they can afford.

Colombi and Wood's (2011) study found that employees at 29 large worksites enrolled in wellness programs with the largest number of obese employees had the highest number of episodes of care (348.4) per 1,000 than did the average weight employees. That totals an annual cost of just over \$1,250 per employee. The study demonstrated that higher rates of obesity among employees contributed to more use among health care plans and more use of sick days than for normal weight individuals.

The impact of obesity on the health care system and the job market is clear. As Americans grow bigger and morbid obesity rages out of control, excessive health care spending, lost days at work, lost productivity, and excessive health care spending are just some of the adverse effects felt by employers. Small business owners and struggling companies could see a potential drain on their finances in the future from obese employees who will not enroll in wellness programs or reduce their weight. Potential drains on employers could come from excessive health care spending and increase in health care plans.

\section{Obesity and Obesity Management for Leadership}

\subsection{The Role of the Health Care Leader in Preventing Obesity}

Health care leaders have an essential role in preventing obesity and obesity related illness. Health care leaders are in a prime position to educate, promote cost savings, and lead creative programs for the management and prevention of obesity (Yang \& Nichols, 2011). Obesity costs businesses an average of $\$ 13$ million a year (Jitendra, Courtney, Kathryn, Mithilesh, \& Bharat, 2011). With costs such as these, it is vital that administrators and nurse managers, as well as stakeholders be aware of programs and cost-cutting measures that can be implemented to reduce the costs associated with obesity. Administrators are in key positions to develop programs that help patients lose weight, manage diets, and offer support groups. These resources are invaluable assets when combating a multi-million dollar cost basis (Natarajan, Mukherjee, \& Sen, 2010). Developing a socially responsible approach to childhood obesity is fast becoming a management obligation (Crane \& Kazmi, 2010). Nurse managers have an opportunity to consider interventions that promote a climate favorable to improved health habits by facilitating and supporting healthy lifestyle choices (nutrition and physical activity) and environmental changes (Zapka, Lemon, Magner, \& Hale, 2009).

As the CEO of Mississippi Baptist Medical Center, a 320-bed full service medical center located in the heart of downtown Jackson, MS, obesity is a quality reason for concern. As the leading state in obese adults (CDC, 2011), MS has a high rate of obesity-related diseases and complications. As the CEO, it is within that role that a guided program should be put forth to put obesity as a priority for education, prevention, and quality initiatives in the hospital to meet AHRQ, CDC, and Healthy People 2020 guidelines. As the CEO, it is imperative that a program be put in place to guide others in the fight against obesity. Gearing nurses toward prevention in discharge teaching is one solution to obesity prevention. Physician counseling of patients while in the hospital and on discharge is another. Task forces on obesity and other related diseases are necessary to oversee the initiation of educational programs offered for patients such as self-help groups and support groups. At Baptist, as the CEO, the main responsibility is maintaining an operating agenda for the quality care of obese patients by providing the services necessary for prevention and reduction of obesity as a disease.

\subsection{Quality Indicators for Performance Improvement}

The National Guideline Clearinghouse (2010) has developed performance indicators for obesity education 
upon discharge from inpatient settings. Administrators need to be aware of these standards and strive to lead the hospital to meet these measures and exceed the standard. The guideline states "Prevention and management of obesity (mature adolescents and adults): percentage of patients with a documented elevated body mass index (BMI) who receive education and counseling for weight loss strategies, which include nutrition, physical activity, lifestyle changes, medication therapy and/or surgery” (National Guideline Clearinghouse, 2010). The measure is used to document the number of patients who receive discharge education about their obesity after an inpatient stay. Clinical literature supporting the measure was used to establish the guideline (Categories IA-II). The prevalence of overweight and obese people is increasing worldwide at an alarming rate in both developing and developed countries. Environmental and behavioral changes brought about by economic development, modernization and urbanization have been linked to the rise in global obesity. Obesity is increasing in children and adults, and true health consequences may become fully apparent in the near future (National Guideline Clearinghouse, 2010). Obesity has become a national epidemic in the U.S. with $32 \%$ of non-institutionalized adults being obese, and 66.3\% being overweight or obese. The most recent data suggest that $17 \%$ of adolescents age 12 to 19 years are overweight and an additional $16 \%$ are at risk for overweight. Obesity is the second leading cause of preventable death in U.S., with only tobacco use causing more deaths. More than 110,000 deaths per year are associated with obesity. The economic impact of obesity and its related conditions on the U.S. economy is staggering and has been estimated at about $\$ 118$ billion in the late 1990 s, or about $12 \%$ of the national health care budget, according to the Worldwatch Institute in 2000 (National Guideline Clearinghouse, 2010).

The suggested period for advice is over a 12-month period. The program development includes lifestyle changes, dietary modifications, and chronic disease management if applicable. Reviewing the medical record to determine who has had the BMI >25 and assigning nurse educators to discuss life issues with the patients can greatly impact the financial effect of obesity (National Guideline Clearinghouse, 2010). Weight management will have to be documented and BMI will have to be documented. It will be clinical staff's responsibility to document these findings in the clinical record. However, administration will have to follow through with the implementation of the quality improvement program to determine if the discharge teaching is being done.

A second quality improvement incentive from the National Guideline Clearinghouse (2010) is "Adult body mass index (BMI) assessment: percentage of members 18 to 74 years of age who had an outpatient visit and who had their BMI documented during the measurement year or the year prior to the measurement year." This is important because upon the patient's visit to the physician in the clinic, BMI should be documented routinely. Using this method, the physician is able to follow the addition or loss of weight and counsel the patient accordingly. The physician in the clinic is then able to see a progression and stay on top of chronic diseases, possibly saving health care dollars.
In the pursuit of improved operational performance and higher customer satisfaction, Six Sigma has been recognized as a systematic and structured methodology that attempts to improve process capability through focusing on customer needs. It has been described as an approach for organizational change, which incorporates elements of quality management and business process reengineering. The key concepts of Six Sigma are define, measure, analyze, design, and verify. When defining an obesity quality improvement program, it is important to follow this design. Executive support is essential to the success of the project (Jones, Parast, \& Adams, 2010).The vital component in developing a plan, do, check, act (PDCA) performance improvement plan for obesity is that nurses, physicians, and ancillary staff become involved in the program. Administrators must make sure guidelines are being met.

\section{Strategies for Improvement Action Plan}

Administrators need a strategy for combatting the problem of obesity. One strategy for combating obesity is to provide discharge teaching for all obese patients who are admitted to the hospital and clinic. By targeting patients in the hospital and clinic, physicians and nurses can educate patients on the benefits of a healthy diet and physical exercise. There is also the benefit of a nutritionist and social services for assistance with those patients who need help with food choices or who cannot afford healthy food. However, nothing will change unless the patient is motivated to change his or her behavior. A motivation factor can be several things. Motivation can be driven by money, the need for good health, and the desire to look better. Finding the patient's motivation will help in motivating the patient to lose weight. Also, creating some incentives such as gift cards for reaching a certain number of pounds or a free spa day for losing so many pounds can also be an incentive to lose weight for some people. Gas cards can also be substituted for spa cards. Administrators have to be in touch with patients' needs to determine what will work best for them.

Another idea for solving the problem would be to offer a weekly seminar on weight loss and diet program headed by a physician, nurse, and nutritionist. This could likely be successful. Adding a second benefit of an exercise program could make the program even more successful. Many administrators have seen the patient census increase as well as the reputation of the hospital improve by offering such programs as diet programs and self-help programs. With the advent of a physician-led program, the administrator can certainly be assured of success.

The strengths of such programs are that they increase the health and well-being of patients admitted to the hospital, decrease the cost of health care associated with obese patients, and reduce the risk of obesity-related chronic diseases. The weaknesses are that patients must be motivated to change and not all patients are motivated to change. Obesity habits are strong and eating habits can be hard to break. Healthy eating versus unhealthy eating can be difficult to transition to and without continued support; some patients may not continue the program. The opportunities are there for continued expansion and 
delivery of high quality patient care. Opportunities for boxed meal plans, liquid diets, combination diets, and other types of medically supervised diets can be supported. Threats include internal staff members who do not record BMI or weights on patients admitted to target those who need education. Patients may not always respond positively to an attempt to educate about obesity and may find it offensive and an insult.

As CEO, it is vital that in this role he or she follows through with implementing key programs and policies to target obesity. The timeline for obesity prevention would be within six months. Within three months a quality management program should be in place and within six months a program for the obese patient such as diet training or physical training should be implemented. Employee training, employee benefits such as free gym memberships, free diet treatment, and incentives to lose weight should be a priority for the CEO. This is to reduce time off from work, lost productivity, and workers' compensation.

\section{Conclusion}

Obesity is a rapidly increasing problem that is plaguing the U.S. Several federal agencies have targeted obesity prevention as a national goal for quality health care. In order to meet this goal, the CEO of any hospital must be proactive in outreach programs, in-house prevention programs, and a quality healthy agenda for the prevention of obesity. Promotion of obesity prevention can be done in numerous ways. As the CEO of Baptist Medical Center in Jackson, MS, the leading state for obesity, the role of the CEO should be to provide support to all the staff and develop in-house agendas for combating the spread of obesity. Obesity is an emerging epidemic that must be addressed by managers and clinicians alike. One way to address obesity is to develop action kits that address lifestyle, behaviors, and physical activity. Finding a solution for those that are obese and have limited access to medical care, exercise programs, or have little money to buy healthy foods can be challenging. However, with the right combination of programs and offerings for patients, these problems can be solved. Offering self-help groups, exercise programs, and support groups for the obese patient is a start. Administrators have to take the lead on this and respond to this crisis appropriately with all attention on getting the epidemic under control so that spending and wasted medical dollars can be controlled. For the actively involved CEO, being a good role model and supporting staff within the hospital is also important as staff often is overweight and contribute to lost wages. Starting employer-based incentives to reduce the number of overweight employees is one way to initiate costsavings. In the end, it is up to the leaders to take a stand.

\section{Statement of Competing Interests}

We declare that we have no competing interests.

\section{References}

[1] Agency for Health Care Research \& Quality. (2011). National health care qualities and disparities report. Retrieved from
http://nhqrnet.ahrq.gov/nhqrdr/jsp/nhqrdr.jsp?catId=10109\&msrId $=90104 \&$ tableTypeId $=1 \&$ msridRO=90102\&tableTypeRO=1\&Pop CatIdCB $=0 \#$ snhere.

[2] Bhattacharya, J. \& Sood, N. (2011). Who pays for obesity? Journal of Economic Perspectives, 25(1), 139-158.

[3] Centers for Disease Control. (2011). Adult obesity. Retrieved from http://www.cdc.gov/obesity/data/adult.html.

[4] Colombi, A. M. \& Wood, G. C. (2011). Obesity in the workplace: impact on cardiovascular disease, cost, and utilization of care. American Health \& Drug Benefits, 4(5), 271-277.

[5] Crane, A. \& Kazmi, B. (2010). Business and children: mapping impacts, managing responsibilities. Journal of Business Ethics, 91(4), 567-586.

[6] Dolinsky, D. H., Siegariz, A. M., Perrin, E., \& Armstrong, S. C. (2011). Recognizing and preventing childhood obesity. Contemporary Pediatrics, 28(1), 32-42.

[7] Farley, Thomas A.; Dowell, Deborah 2014). Preventing Childhood Obesity: What Are We Doing Right? American Journal of Public Health, 2014 Sep; 104 (9): 1579-83.

[8] Gade, W., Gade, J., Collins, M., Schmidt, J. \& Schupp, N. (2010). Focus: obesity and metabolic syndrome. Failures of feedback: rush hour along the highway to obesity. Clinical Laboratory Science, 23(1), 39-50.

[9] Haemer, M., Cluett, S., Hassink, S. G., Liu, L., Mangarelli, K.,...Weill, B. (2011). Building capacity for childhood obesity prevention and treatment in the medical community: call to action. Pediatrics, 128, 571-577.

[10] Healthy People 2020. (2011). Goals and objectives. Retrieved from http://www.healthypeople.gov/2020/topicsobjectives2020/objectiv eslist.aspx?topicId=29.

[11] Jay, M., Gillespie, C., Schlair, S., Sherman, S., \& Kalet, A. (2010). Physicians' use of the 5As in counseling obese patients: is the quality of counseling associated with patients' motivation and intention to lose weight? BMC Health Services Research, 10, 159.

[12] Jitendra, M., Courtney, B., Kathryn, M., Mithilesh, M., \& Bharat, M. (2011). Obesity in the workplace: an international outlook. Advances in Management, 4(3), 7-17.

[13] Jones, E. C., Parast, M. M., \& Adams, S. G. (2010). A framework for effective Six Sigma implementation. Total Quality Management \& Business Excellence, 21(4), 415-424.

[14] Lavizzo-Mourey, R. \& Levi, J. (2011). F as in fat: how obesity threatens America's future. The Robert Wood Johnson Foundation, Retrieved from

http://www.healthyamericans.org/assets/files/TFAH2011FasInFat 10.pdf.

[15] Lazarou, C. \& Kouta, C. (2010). The role of nurses in the management and prevention of obesity. British Journal of Nursing (BJN), 19(10), 641-647.

[16] Lovejoy, J. (2011). Five steps health care leaders can take to address childhood obesity. American Health \& Drug Benefits, 4(1), 50-2.

[17] Marchiondo, Kathleen1Stemming the Obesity Epidemic: Are Nurses Credible Coaches? MEDSURG Nursing. May/Jun2014, Vol. 23 Issue 3, p155-158.

[18] Meires, J. \& Christie, C. (2011). Contemporary approaches to obesity treatment. The Nurse Practitioner, 36(9), 37-46.

[19] Murimi, M. W. \& Harpel, T. (2010). Practicing preventive health: the underlying culture among low-income rural populations. The Journal of Rural Health: The Official Journal of the American Rural Health Association and the National Rural Health Care Association, 26(3), 273-282.

[20] Natarajan, V., Mukherjee, A., \& Sen, K. C. (2010). Drivers of obesity: an empirical investigation across US Metropolitan Statistical Areas. Proceedings of the Northeast Business \& Economics Association, 21, 445-446.

[21] National Guideline Clearinghouse. (2010). Prevention and management of obesity. Retrieved from http://www.qualitymeasures.ahrq.gov/content.aspx?id=27639\&sea rch=obesity

[22] Skolnik NS; Ryan DH (2014). Pathophysiology, epidemiology, and assessment of obesity in adults. The Journal Of Family Practice 2014 Jul; Vol. 63 (7), pp. S3-S10.

[23] U.S. Preventive Service Task Force. (2007). Screening for obesity in adults. Retrieved from http://www.uspreventiveservicestaskforce.org/uspstf/uspsobes.htm \#summary. 
[24] Wandia F, Ettyang G, Mbagaya G, PREVALENCE OF AND FACTORS ASSOCIATED WITH OVERWEIGHT AND OBESITY AMONG NURSERY SCHOOL CHILDREN AGED 3-6 YEARS IN ELDORET MUNICIPALITY. African Journal Of Food, Agriculture, Nutrition \& Development [serial online]. August 2014;14(5):2057-2071. Available from: Academic Search Complete, Ipswich, MA. Accessed December 5, 2014
[25] Yang, Y. T. \& Nichols, N. M. (2011). Obesity and health system reform: private vs. public responsibility. Journal of Law, Medicine \& Ethics, 39(3), 380-386.

[26] Zapka J. M., Lemon, S. C., Magner, R. P., \& Hale, J. (2009). Lifestyle behaviours and weight among hospital-based nurses. Journal of Nursing Management, 17(7), 853-60. 